\title{
Introducing an innovative design to examine human-environment dynamics of food deserts responding to COVID-19
}

Chyi-Lyi (Kathleen) Liang ${ }^{\text {a* }}$

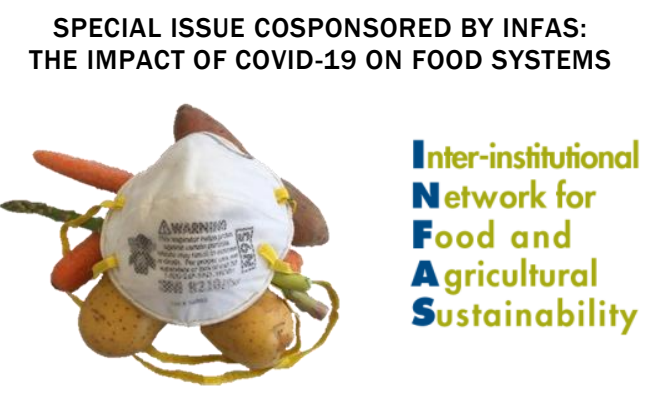

Center for Environmental Farming Systems

Lyubov Kurkalova ${ }^{\mathrm{b}}$ and Leila Hashemi Beni ${ }^{\mathrm{c}}$

North Carolina Agricultural and Technical State University

Timothy Mulrooney d

North Carolina Central University

Manoj Jha, ${ }^{\mathrm{e}}$ Haoran Miao, ${ }^{\mathrm{f}}$ and Gregory Monty $\mathrm{g}$

North Carolina Agricultural and Technical State University

Submitted August 24, 2020 / Revised December 13, 2020, and January 15 and 17, 2021 /

Accepted January 17, 2021 / Published online March 23, 2021

Citation: Liang, C.-L., Kurkalova, L., Hashemi Beni, L., Mulrooney, T., Jha, M., Miao, H., \& Monty, G.

(2021). Introducing an innovative design to examine human-environment dynamics of food deserts

responding to COVID-19. Journal of Agriculture, Food Systems, and Community Development, 10(2), 123-133.

https://doi.org/10.5304/jafscd.2021.102.037

Copyright (C) 2021 by the Authors. Published by the Lyson Center for Civic Agriculture and Food Systems. Open access under CC-BY license.

\begin{abstract}
Food desert communities face persistent barriers in accessing affordable fresh and healthy foods, particularly for the underserved and limited-resourced

a * Corresponding author: Chyi-Lyi (Kathleen) Liang, Kellogg Distinguished Professor and Director of Center for Environmental Farming Systems, North Carolina Agricultural and Technical State University; 1601 East Market Street; Greensboro, NC 27411 USA; +1-336-285-4683; cliang@,ncat.edu

b Lyubov Kurkalova, Professor, North Carolina Agricultural and Technical State University; lakurkal@,ncat.edu

c Leila Hashemi Beni, Assistant Professor, North Carolina Agricultural and Technical State University; lhashemibeni@ncat.edu

$\mathrm{d}$ Timothy Mulrooney, Associate Professor, North Carolina Central University, tmulroon@nccu.edu
\end{abstract}

minority population. This research brief proposes an integrated design concept examining humanenvironment dynamics of food deserts to identify

\footnotetext{
e Manoj Jha, Associate Professor, North Carolina Agricultural and Technical State University; mkjha@ncat.edu

${ }^{\mathrm{f}}$ Haoran Miao, Postdoctoral Fellow, Department of Civil, Architectural and Environmental Engineering, North Carolina Agricultural and Technical State University; hmiao@ncat.edu

g Gregory Monty, Director of Center for Energy Research and Technology, North Carolina Agricultural and Technical State University, ghmonty@ncat.edu

\section{Funding Disclosure}

This material is based on work supported by the National Science Foundation under Grant No. 1824949 and Kellogg Foundation Endowment. Any opinions, findings, and conclusions or recommendations expressed in this material are those of the author(s) and do not necessarily reflect the views of the National Science Foundation and Kellogg Foundation.
} 
strategies that would provide effective planning to prevent, prepare for, or respond to disruptive events such as natural disasters or pandemics in the future. The North Carolina example we describe identifies the potential overlapping areas between food deserts and number of COVID-19 cases to demonstrate how an unpredictable event could exacerbate public health in food desert communities to a greater extent than in communities with better food access, availability, and accessibility. The improved understanding of food systems could help in addressing unprecedented challenges such as those due to the COVID-19 crisis.

\section{Keywords}

Food Insecurity, Food Desert, COVID-19, Pandemic, Food Systems, Integrated Design

A Brief Overview of Food Issues in the U.S. Unpredictable events such as the COVID-19 pandemic and market volatility have paralyzed many food supply chains, which also widen the gaps of food insecurity across socio-economic and geographical characteristics (Thilmany, Canales, Low, \& Boys, 2020; Ziliak, 2020). There is an urgent need to seek innovative strategies and approaches that will improve well-being and health for individuals, families, communities, and the environment by alleviating gaps corresponding to food access, availability, and affordability.

One of the commonly used community-level measures of food access is the concept of the food desert. According to the U.S. Department of Agriculture (USDA), a food desert is a geographic area characterized by both low income and poor access to healthy food (USDA, 2020). The online Food Access Research Atlas, developed by the USDA, Economic Research Service (USDA ERS), is a tool to map food deserts at the census tract resolution for several alternative measures of low income and low access (USDA ERS, 2020).

In this research brief, we propose a coupled human and natural systems (CHANS) integrated design (Liu et al., 2007) to examine humanenvironment dynamics of food deserts to identify strategies that would provide effective planning to prevent, prepare for, or respond to disruptive events such as natural disasters or pandemics in the future. The CHANS approach has been identified as a potent framework to address the design for sustainability of regional planning, agriculture, and soil and water resource management (Kline et al., 2017; Lu et al., 2019) In this paper, we utilize data from North Carolina as an example that highlights how an unpredictable event could exacerbate public health in food desert communities. We then explain how the model focused on food deserts could be developed using a CHANS framework and the types of data that the model could use. The initial concept presented here, if fully developed and implemented, could help to mitigate the challenges of food deserts. What is needed is an integrated system design to provide a platform for communities to do the following four activities:

1. Understand the factors influencing the interactions between human decisions in food production and consumption.

2. Evaluate how our choices in agricultural operations and food consumption relate to changes in environmental quality.

3. Gather and maintain concise and consistent longitudinal data to identify existing practices and policies that support or hinder alleviating food insecurity.

4. Reinvigorate new policies and community practices to assist people and organizations in planning and preparing to avoid and reduce the disparity of well-being and health due to food insecurity.

\section{Summarized Literature Review for Food Deserts}

Food access is a critical component in community planning, and the issues are significantly different in rural and urban areas (Pothukuchi, 2009). Mergers and acquisitions in the food retail industry have climbed since the late 1990s, resulting in a higher concentration of sales among fewer chain stores (DePillis, 2013; Harris, Kaufman, Martinez, \& Price, 2002; USDA, 2017). Most large chain stores such as supercenters and supermarkets are in areas of high population density, while independent and small-scale neighborhood grocery stores are more likely established in low-income neighborhoods and rural regions (Block \& Kouba, 2006; Chung \& Myers, 1999; Powell, Auld, Chaloupka, O’Malley, \& Johnston, 2007). The shifting concen- 
tration of large-format chain stores has created increasing challenges to other types of food stores, which links to problematic food access in over half of U.S. counties (USDA, 2017, 2020). Scholars have pointed out the urgency to conduct more studies examining the potential impacts of the food retail industry on food access, particularly in remote rural areas and low-income neighborhoods (Dunn, Dean, Johnson, Leidner, \& Sharkey, 2012; Larson, Story, \& Nelson, 2009), and on consumers' decisions in purchasing healthy foods.

The COVID-19 crisis has revealed long-standing food insecurity issues, resulting in immediate change in both the food supply chain and food consumption. The production of fruits and vegetables, one of the most labor-intensive sectors of agriculture, has been adversely affected by the pandemic-induced disruptions in the farm labor supply (Ridley \& Devadoss, 2020). News reports and videos have revealed commercial farms dumping excess milk or fresh produce, while grocery stores are left with empty shelves and people waiting in long lines to acquire food assistance (McKay, 2020; Yaffe-Bellany \& Corkery, 2020). In response, consumers appear to place less importance on nutritional value, instead purchasing more convenient, comforting food such as pizza and ice cream (Ellison, McFadden, Rickard, \& Wilson, 2020). The desperation of seeking food assistance seems to be worse in socially disadvantaged, limited-resourced, and underrepresented communities (Gundersen, Hake, Dewey, \& Engelhard, 2020; Jablonski et al., 2020; Ziliak, 2020).

\section{Understanding Issues about Food Deserts}

The literature on food deserts keeps expanding (Freedman et al., 2016; Hsiao, Sibeko, \& Troy, 2019; Walker, Keane, \& Burke, 2010). One of the earlier systematic reviews of food desert research, by Beaulac, Kristiansson, and Cummins (2009), synthesized the findings of studies that used geographic or market-basket approaches published between 1966 and 2007. The review discussed the characteristics of food deserts with a focus on the links to social and economic factors, and pointed out that categories and scenarios of food deserts varied significantly across countries. This early review also revealed that low-income, minority, and rural populations seemed to face more challenges in accessing affordable foods in the U.S.

Topics of more recent food desert studies range from geographical distribution to socioeconomic profiles to human behaviors to health implications, which we will now discuss. These studies have evaluated how food desert incidence is related to the geographic distribution of alternative food retailers (Colón-Ramos et al., 2018; Coughenour, Bungum, \& Regalado, 2018; McDermot, Igoe, \& Stahre, 2017; Vaughan, Cohen, GhoshDastidar, Hunter, \& Dubowitz, 2017), and have documented the shopping behavior of food desert residents with barriers in accessing transportation and varieties of grocery stores (Gray et al., 2018; Hardin-Fanning \& Gokun, 2014; Ma et al., 2018; Zachary, Palmer, Beckham, \& Surkan 2013). The geographic information system (GIS) is one of the most adopted techniques to measure households' spatial accessibility to food retail stores (e.g., Giang, Karpyn, Laurison, Hillier, \& Perry, 2008; Michimi \& Wimberly, 2010; Mulrooney, Beratan, McGinn, \& Branch, 2017; Xu, 2014; Zenk, Schulz, Israel, James, Bao, \& Wilson, 2005).

The disparities in diet and diet-related health outcomes between food desert and non-food desert communities (including the disparities in prevalence of chronic diseases) have been a subject of significant research (Abeykoon, Engler-Stringer, \& Muhajarine, 2017; Hanson et al., 2018; Liese et al., 2018; Morris et al., 2019; Testa, 2019). Multiple studies ask questions about the effectiveness of the policy interventions aiming to improve the access to healthy, affordable food for the people living in and around food desert areas (Freedman et al., 2016; Hsiao et al., 2019; Smith, Miles-Richardson, Dill, \& Archie-Booker, 2013). Despite the significant academic and practitioner interest, effective approaches to the alleviation of the food insecurity problem are still a puzzle.

We propose a novel approach to examine community food systems that explores the potential to promote and support local farmers so that they increase the supply and variety of fresh produce to community-based food stores. It has been challenging to identify empirical studies that attempted to simulate the potential of shifting existing food production at the local level to accommo- 
date small-scale food retail stores in rural or urban areas. A complementary research question arises about the environmental impacts, such as changes in soil and water quality, of re-purposing existing farmland or vacant sites to diversify local food supplies. Answering these questions requires a new approach, one that encompasses the human-environmental relationship of food deserts.

\section{The Relationship between} COVID-19 and Food Deserts Using North Carolina as an Example

The COVID-19 pandemic highlighted the vulnerability of food desert communities, and we are proposing a new approach to look at the issue. This research brief reports some baseline information in North Carolina as an example. The state is chosen for its data availability. While food desert maps are available nationally at the census tract level, only some states, including North Carolina, report COVID-19 data at a relatively fine spatial scale, making a spatially explicit, GIS analysis possible.

The following data have been used for creating the example:

- Data for COVID-19, as of July 7, 2020, at the ZIP code level (the finest scale currently available) from the COVID-19 North Carolina Dashboard ${ }^{1}$ and linked to polygon zip codes stored in a GIS.

- The food desert/non-food desert designation at a more granular, census tract scale, from the USDA Food Access Research Atlas (USDA ERS, 2020). Low-access regions are distinguished between urban regions $(>1$ mile or $1.6 \mathrm{~km})$ and rural $(>10$ miles or $16 \mathrm{~km}$ ) and agglomerated into a single database representing food deserts.

- These COVID-19 rates and food deserts are highlighted in the map (Figure 1).

Because the scales at which data for food deserts (census tract) and COVID-19 rates (zip code) are collected do not match, GIS methods were used to overlay two data on top of each other and to find zip codes that were related to each USDA food desert census tract, highlighting food deserts in this study at the zip code scale. We found that $16.9 \%$ of food desert census tracts $(367$ out of 2,174) were classified as food deserts, while $14.9 \%$ of zip codes (114 out of 763 ) were classified as food deserts.

The number of COVID-19 cases was compared between the food desert zip codes and nonfood desert zip codes in the study area and analyzed using the two-sample t-test to determine if the two population means are equal. The results showed distinct differences between COVID-19 incidence rates between the food desert and nonfood desert areas (Table 1). In North Carolina, the food desert communities appear to have a higher number of COVID-19 cases. This result illustrates that there are overlapping areas between food deserts and the areas of COVID-19 cases and shows how an unpredictable event could exacerbate public health in food desert communities to a greater extent than in non-food desert communities (Figure 1).

\section{Proposing an Innovative Design to Study Human-Environmental Relationship of Food Deserts and to Enhance Community Planning}

Agriculture and food systems face a combination of multiple constraints such as weather and climate variations, domestic and international market volatilities, biophysical and/or geographical and tech-

${ }^{1}$ https://covid19.ncdhhs.gov/dashboard 
Figure 1. The Overlapping Effect Between the Number of COVID-19 Cases and Food Desert Communities

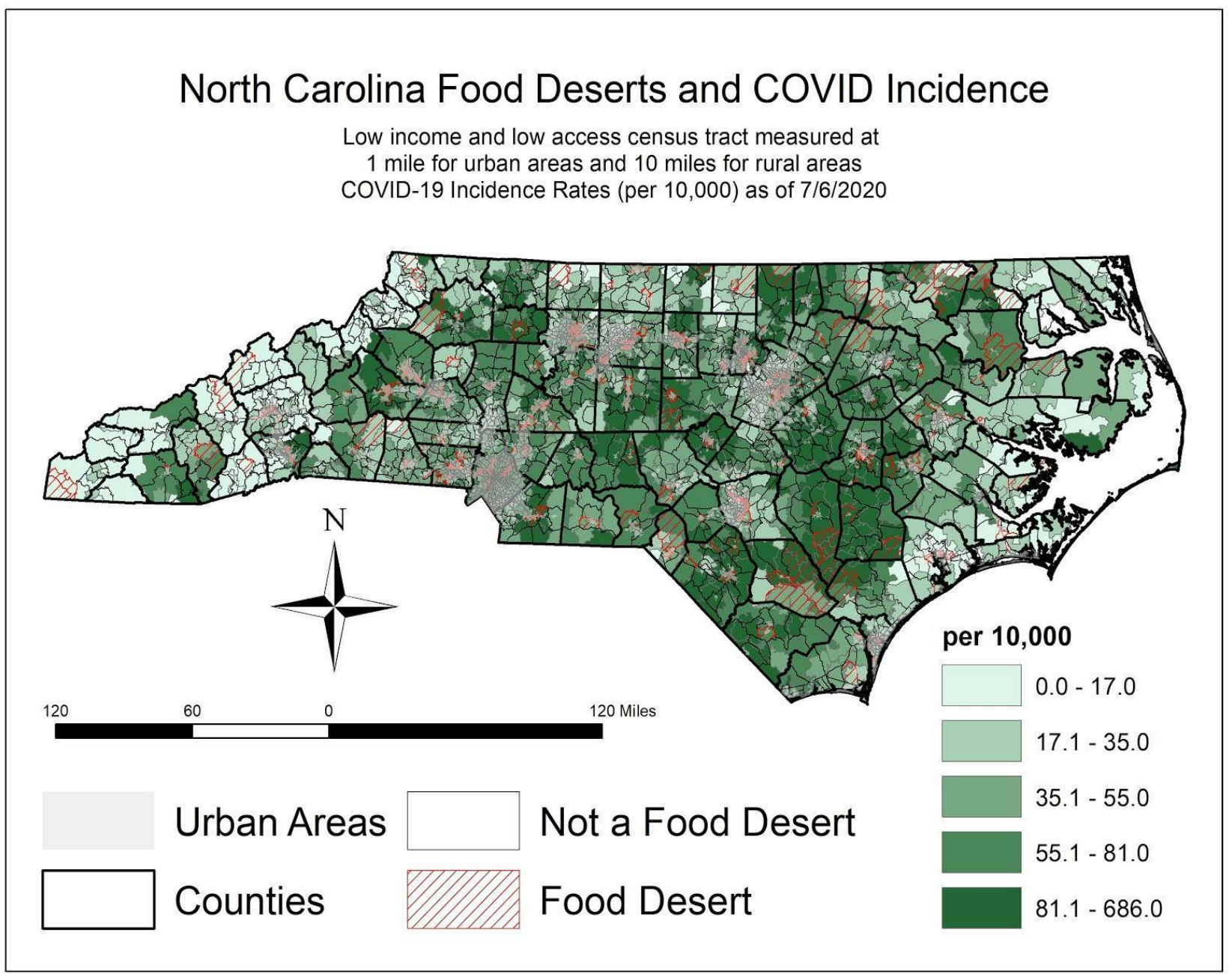

nology restrictions, and mixed scale of operations and management. We hypothesize that analyzing food desert phenomena in an integrated view that couples human and natural systems will significantly improve the understanding of how to achieve a balance between food security, maximizing production, and minimizing negative environmental impacts. It would be beneficial for communities to build an integrated and scenario-adjustable planning framework to include multidisciplinary datasets and analytical and simulation tools to tackle food system issues during the planning process that will consider resiliency in planning for prevention, preparation, prescription, responsiveness, and recovery during a shock like a hurricane or a pandemic like COVID-19.

The development of an integrated research- based concept for communities to use to examine the interactions between social, economic, and environmental components that correspond to the four objectives described in the introduction could serve as the basis for food systems change that will mitigate the negative impacts of shocks on various community scenarios. The following four stages describe a proposed process to achieve the objectives:

Stage 1: Geo-code the spatial-temporal database for both human and natural factors that jointly influence food availability, accessibility, affordability, and accountability. The human factors might include socio-economic characteristics (e.g., demographics, family compositions) and policy orientations (e.g., zoning, transportation infrastructure). 
The natural factors might include land use capacity (e.g., residential versus commercial), land characteristics (e.g., slope, soil), farming activities (e.g., types of farms around the communities), distribution and features of food retailers (e.g., distance and protection from temperature and moisture variations), and community infrastructure such as internet access and communication methods.

Stage 2: Develop an integrated modeling system to link human systems (consumption and production models) to natural systems (land use and GIS models) to better understand and respond to food desert issues. This stage involves a thorough evaluation of existing practices and simulation modeling methods based on research evidence. Some of the robust methods include agent-aased modeling (Muto, Bolivar, \& González, 2020; Widener, Metcalf, \& Bar-Yam, 2013), which applies multiple factors from social-economic-environmental aspects to identify opportunities for balanced and integrated decision-making.

Stage 3: Test the modeling system to validate the reliability and robustness of the method for the study area of interest. This stage involves using data gathered from a food desert community to test the modeling formula and whether the out- comes are reasonable. There are many datasets publicly available for such works. The datasets will be introduced in the following section.

Stage 4: Disseminate the modeling outcome through outreach activities with stakeholders via hands-on demonstrations, interactive discussions, and visualization maps like Figure 1.

Figure 2 presents an example of what an integrated thinking-design platform could look like. Each community has its characteristics to define conditions, influential factors, and the decisionmaking process. The key is to make sure each community can recruit ideas across all stakeholders to enlist a comprehensive assessment of gaps and opportunities for meaningful collaborations.

The dynamics within human systems: Given the modeled condition of a shifting food retail industry and profile in each community, it is possible to simulate farmers' production decisions to set aside a certain percentage of land, for example to produce a vegetable mix. Local food retailers provide a reasonable inventory level for purchase by local households. Each household makes decisions on where to buy and what to buy, given the produce prices and food retailers' locations (food

\section{Figure 2. High-Level Schematic of the Dynamics of Coupled Human and Natural Systems}

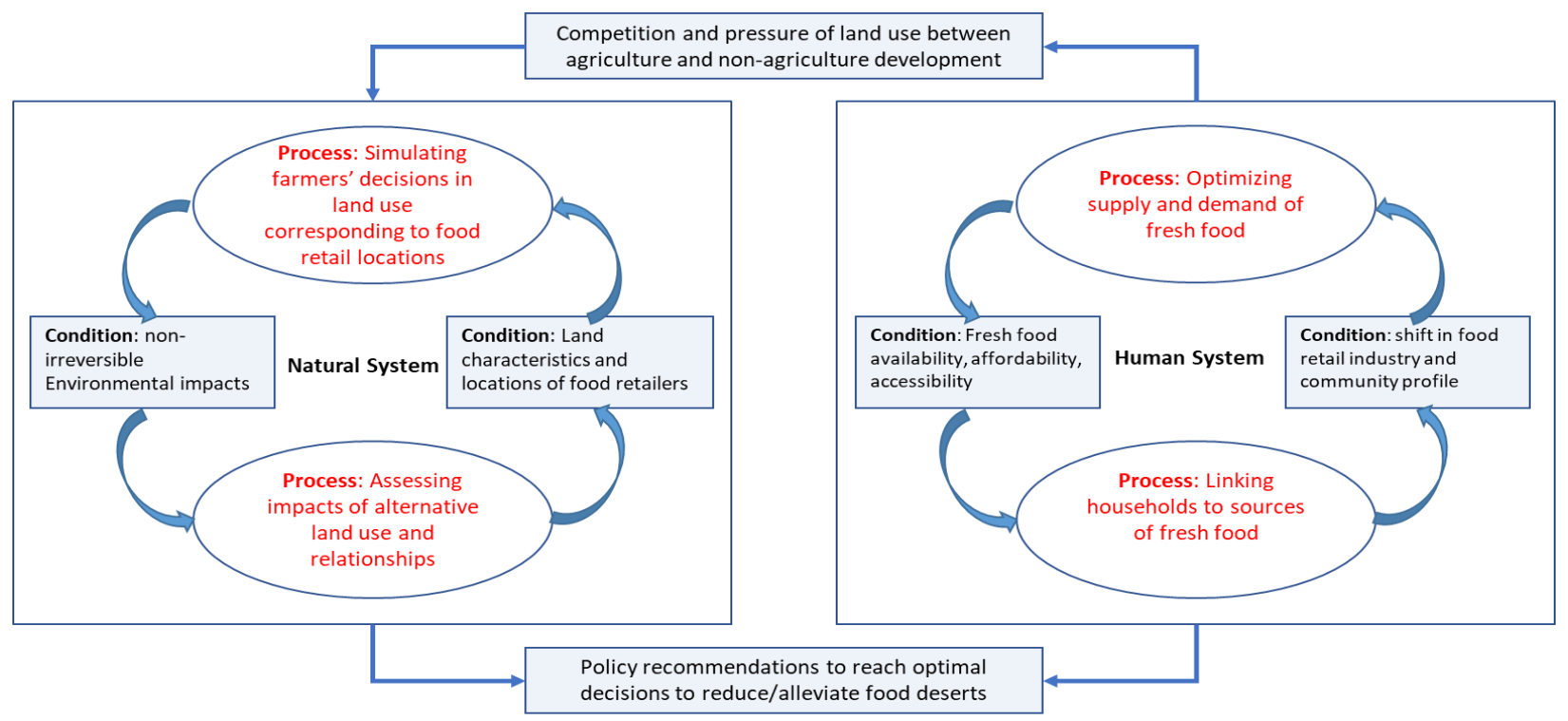


availability, affordability, accessibility). Household decisions on food purchases provide feedback to farmers and food retailers who then adjust their production and inventory levels.

\section{The dynamics within natural systems: Given} the condition of land characteristics and food retail locations, the natural system can be modeled using a biophysical model, which considers farmers' decisions to change the use of farmland (for example, for vegetable production or commercialization) and other input parameters such as soil characteristics, crop choices, and climate. The model will capture impacts of farmers' land-use decisions on hydrology and the environment, crop and vegetable yield potential, and land and water quality (soil loss, soil water content, nutrients, runoff) with various spatiotemporal scales.

The plan for evaluation of the platform also needs to be well developed following the standard scientific process (Groenveld et al., 2017) to

1. Generate and validate individual components of the modeling and decision-making platform using unbiased and representative sets of input and observed historical data;

2. Integrate the components and validate the integrated systematic approaches to benchmark against the USDA's Food Desert Locator and other reliable sources of information; and

3. Use the modeling and decision-making platform to assess the impacts of specific exogenous changes for a set of socialeconomic-environmental scenarios for food deserts versus non-food deserts. Some examples might include the shifts of community planning priorities, community characteristics, population migrations, resource allocation, and development infrastructure.

The model proposed in this article demonstrates how a long-term planning process could positively influence human behaviors within the balance of natural systems when a pandemic like COVID-19 occurs._Each household needs to acquire sufficient information to identify the most logical, convenient, and reasonable path to access healthy food. People living in food deserts often lack knowledge and guidance to become acquainted with different types of food and outlets, or such knowledge may be insufficient to change foodpurchasing behavior, which in turn, could also be shaped by preferences based on health, culture, religion, and family history. Linking consumers to farmers has grown in interest during the COVID19 crisis. Local farmers need to weigh the financial outcomes before transitioning into different types of products and practices. Farmers with proper skills sets, knowledge, equipment, and willingness to change might be able to shift land use to produce vegetables when there is sufficient demand from local food retailers and households, or farmers may sell land for commercial development. Once land structures are changed, effects on soil and water quality are created, often irreversibly. When land use is shifted for either food production or commercial development, land characteristics change. Such change may affect long-term soil fertility by switching the crop patterns.

\section{Data Availability to Support This Approach and Next Steps}

To design and create an integrated platform takes tremendous time and data. Fortunately, there are multiple datasets that could assist in the development of a platform like the one we propose in this article. Table 1 shows an example of a collective spatial-temporal database that could capture the human systems, natural systems, and their interactions. Additional data and information have been proposed by other scholars using focus groups, interviews, and surveys (Beaulac et al., 2009; Lytle \& Sokol, 2017).

\section{Concluding Remarks}

This research brief proposes a concept for an integrated design to examine the human-environment dynamics of food deserts and identify strategies that would provide effective planning to prevent, prepare for, or respond to future disruptive events such as natural disasters or pandemics. Scholars have identified concerns and correlations between food access and health disparity for the popula- 
tions living in food deserts (Allcott et al., 2019; Coleman-Jensen, Rabbitt, Gregory, \& Singh, 2020; USDA ERS, 2019). The North Carolina example we present has identified the potential overlapping areas between food deserts and areas of high COVID-19 cases to demonstrate how an unpredictable event could exacerbate public health in food desert communities to a greater extent than in more food-secure communities.

\section{Acknowledgments}

We are thankful to three anonymous reviewers whose constructive criticism and comments have improved the manuscript.

\section{References}

Abeykoon, A. M. H., Engler-Stringer, R., \& Muhajarine, N. (2017). Health-related outcomes of new grocery store interventions: A systematic review. Public Health Nutrition, 20(12), 2236-2248. https://doi.org/10.1017/S1368980017000933

Allcott, H., Diamond, R., Dubé, J. P., Handbury, J., Rahkovsky, I., \& Schnell, M. (2019). Food deserts and the causes of nutritional inequality. Quarterly Journal of Economics, 134(4), 1793-1844. https://doi.org/10.1093/qje/qjz015

Beaulac, J., Kristiansson, E., \& Cummins, S. (2009). A systematic review of food deserts, 1966-2007. Preventing Chronic Disease, 6(3), A105. https://www.ncbi.nlm.nih.gov/pmc/articles/PMC2722409/

Block, D. \& Kouba, J. (2006). A comparison of the availability and affordability of a market basket in two communities in the Chicago area. Public Health Nutrition, 9(7), 837 -845. https://doi.org/10.1017/phn2005924

Coleman-Jensen, A., Rabbitt, M. P., Gregory, C. A. \& Singh, A. (2020). Household food security in the United States in 2019 (USDA Economic Research Report No. ERR-275). Retrieved from https://www.ers.usda.gov/publications/pub-details/?pubid=99281

Chung, C. \& Myers, S. L. (1999). Do the poor pay more for food? An analysis of grocery store availability and food price disparities. Journal of Consumer Affairs, 33(2), 276-296. https://doi.org/10.1111/j.1745-6606.1999.tb00071.x

Colón-Ramos, U., Monge-Rojas, R., Stevenson, T. R., Burns, H., Thurman, S., Gittelsohn, J., \& Gurman, T. A. (2018). How do African-American caregivers navigate a food desert to feed their children? A photovoice narrative. Journal of the Academy of Nutrition and Dietetics, 118 (11), 2045-2056. https://doi.org/10.1016/j.jand.2018.04.016

Coughenour, C., Bungum, T. J., \& Regalado, M. N. (2018). Healthy food options at dollar discount stores are equivalent in quality and lower in price compared to grocery stores: An examination in Las Vegas, NV. International Journal of Environmental Research and Public Health, 15(12), 2773. https://doi.org/10.3390/ijerph15122773

DePillis, L. (2013, July 28). Supermarkets are merging again: What does that mean for your grocery bill? Washington Post. Retrieved from https://www.washingtonpost.com/news/wonk/wp/2013/07/28/supermarkets-are-merging-againwhat-does-that-mean-for-your-grocery-bill/

Dunn, R. A., Dean, W. R., Johnson, C. M., Leidner, A., \& Sharkey, J. R. (2012). The effect of distance and cost on fruit and vegetable consumption in rural Texas. Journal of Agricultural and Applied Economics, 44(4), 491-500. https://doi.org/10.1017/S1074070800024068

Ellison, B., McFadden, B., Rickard, B. J., \& Wilson, N. L. (2020). Examining food purchase behavior and food values during the COVID-19 Pandemic. Applied Economic Perspectives and Policy, 43(1), 58-72. https://doi.org/10.1002/aepp.13188

Environmental Systems Research Institute (ESRI). (2020). USA median household income (2020) [Map image layer]. Retrieved from https:/ /www.arcgis.com/home/item.html?id=20a60423d37c49ba9253526859ba93e1

Freedman, D. A., Vaudrin, N., Schneider, C., Trapl, E., Ohri-Vachaspati, P., Taggart, M., Cascio, M. A., Walsh, C., \& Flocke, S. (2016). Systematic review of factors influencing farmers' market use overall and among low-income populations. Journal of the Academy of Nutrition and Dietetics, 116(7), 1136-1155. https://doi.org/10.1016/i.jand.2016.02.010

Giang, T., Karpyn, A., Laurison, H. B., Hillier, A., \& Perry, R. D. (2008). Closing the grocery gap in underserved communities: the creation of the Pennsylvania Fresh Food Financing Initiative. Journal of Public Health Management and Practice, 14(3), 272-279. https://doi.org/10.1097/01.PHH.0000316486.57512.bf 
Gray, M. S., Lakkur, S., Howard, V. J., Pearson, K., Shikany, J. M., Safford, M., Gutiérrez, O. M., Colabianchi, N., \& Judd S. E. (2018). The association between residence in a food desert Census tract and adherence to dietary patterns in the REGARDS Cohort. Food and Public Health, 8(4), 79-85. https://www.ncbi.nlm.nih.gov/pmc/articles/PMC6714990/

Groeneveld, J., Müller, B., Buchmann, C. M., Dressler, G., Guo, C., Hase, N., . . Lauf, T. (2017). Theoretical foundations of human decision-making in agent-based land use models-A review. Environmental Modelling \& Software, 87, 39-48. https://doi.org/10.1016/i.envsoft.2016.10.008

Gundersen, C., Hake, M., Dewey, A., \& Engelhard, E. (2020). Food insecurity during COVID-19. Applied Economic Perspectives and Policy, 43(1), 153-161. https://doi.org/10.1002/aepp.13100

Hanson, C., Schumacher, M. V., Lyden, E., Su, D., Furtado, J., Cammack, R., Bereitschaft, B., Van Ormer, M., Needelman, H., McGinn, E., \& Rilett, K. (2018). Fat-soluble vitamins A and E and health disparities in a cohort of pregnant women at delivery. Journal of Nutritional Science, 7. https://doi.org/10.1017/jns.2018.5

Hardin-Fanning, F., \& Gokun, Y. (2014). Gender and age are associated with healthy food purchases via grocery voucher redemption. Rural and Remote Health, 14(3), 2830. https://pubmed.ncbi.nlm.nih.gov/25063239/

Harris, J. M., Kaufman, P. R., Martinez, S. W., \& Price, C. (2002). The U.S. food marketing system, 2002 (Agricultural Economic Report No. 811). Washington, DC: USDA, Economic Research Service. Retrieved from https://www.ers.usda.gov/publications/pub-details/?pubid $=41450$

Hsiao, B., L. Sibeko, \& L. M. Troy. (2019). A systematic review of mobile produce markets: facilitators and barriers to use, and associations with reported fruit and vegetable intake. Journal of the Academy of Nutrition and Dietetics, 119(1), 76-97. https://doi.org/10.1016/j.jand.2018.02.022

Jablonski, B. B. R., Casnovsky, J., Clark, J. K., Cleary, R., Feingold, B., . . W Wentworth, C.. (2020). Emergency food provision for children and families during the COVID-19 pandemic: Examples from five US cities. Applied Economic Perspectives and Policy, 43(1), 169-184. https://doi.org/10.1002/aepp.13096

Kline, J. D., White, E. M., Fischer, A. P., Steen-Adams, M. M., Charnley, S., Olsen, C. S., . . Bailey, J. D. (2017). Integrating social science into empirical models of coupled human and natural systems. Ecology and Society, 22(3), Article 25. https:/ / doi.org/10.5751/ES-09329-220325

Larson, N. I., Story, M. T., \& Nelson, M. C. (2009). Neighborhood environments: disparities in access to healthy foods in the U.S. American Journal of Preventive Medicine, 36(1), 74-81, e10. https://doi.org/10.1016/j.amepre.2008.09.025

Liese, A. D., Lamichhane, A. P., Garzia, S. C. A., Puett, R. C., Porter, D. E., Dabelea, D., . . Liu, L. (2018). Neighborhood characteristics, food deserts, rurality, and Type 2 diabetes in youth: Findings from a case-control study. Health \& Place, 50, 81-88. https://doi.org/10.1016/j.healthplace.2018.01.004

Liu, J., Dietz, T., Carpenter, S. R., Folke, C., Alberti, M., Redman, C. L., . . Taylor, W.W. (2007). Coupled human and natural systems. AMBIO: a journal of the buman environment, 36(8), 639-649. https://doi.org/10.1579/0044-7447(2007)36[639:CHANS]2.0.CO;2

Lu, Z., Broesicke, O. A., Chang, M. E., Yan, J., Xu, M., Derrible, S., . . Crittenden, J. C. (2019). Seven approaches to manage complex coupled human and natural systems: A sustainability toolbox. Environmental Science \& Technology, 53(16), 9341-9351. https://doi.org/10.1021/acs.est.9b01982

Lytle, L., \& Sokol, R. (2017). Measure of the food environment: A systematic review of the field, 2007-2015, Health \& Place, 44, 18-34. https://doi.org/10.1016/j.healthplace.2016.12.007

Ma, X., Sharpe, P. A., Bell, B. A., Liu, J., White, K., \& Liese, A. D. (2018). Food acquisition and shopping patterns among residents of low-income and low-access communities in South Carolina. Journal of the Academy of Nutrition and Dietetics, 118(10), 1844-1854. https://doi.org/10.1016/j.jand.2018.04.017

McDermot, D., Igoe, B., \& Stahre, M. (2017). Assessment of healthy food availability in Washington State-Questioning the food desert paradigm. Journal of Nutrition Education and Behavior, 49(2), 130-136. https://doi.org/10.1016/j.jneb.2016.10.012

McKay, H. (2020, May 8). Why farmers dump food and crops while grocery stores run dry and Americans struggle. Fox News. https://www.foxnews.com/us/farmers-dump-food-grocery-stores-shortage-coronavirus 
Michimi, A. \& Wimberly, M. C. (2010). Associations of supermarket accessibility with obesity and fruit and vegetable consumption in the conterminous United States. International Journal of Health Geographics, 9, 49. https://doi.org/10.1186/1476-072X-9-49

Morris, A. A., McAllister, P., Grant, A., Geng, S., Kelli, H. M., Kalogeropoulos, A., Quyyumi, A., and Butler, J. (2019). Relation of living in a 'food desert' to recurrent hospitalizations in patients with heart failure. The American Journal of Cardiology, 123(2), 291-296. https://doi.org/10.1016/j.amjcard.2018.10.004

Mulrooney, T., Beratan, K., McGinn, C., \& Branch, B. (2017). A comparison of raster-based travel time surfaces against vector-based network calculations as applied in the study of rural food deserts. Applied Geography, 78, 12-21. https://doi.org/10.1016/j.apgeog.2016.10.006

Muto, T. J., Bolivar, E. B., \& González, E. (2020). BDI multi-agent based simulation model for social ecological systems. In F. De La Prieta et al. (Eds.), Highlights in Practical Applications of Agents, Multi-Agent Systems, and Trust-worthiness. The PAAMS Collection. PAAMS 2020 (pp. 279-288). Springer, Cham. https://doi.org/10.1007/978-3-030-51999-5 23

Pothukuchi, K. (2009). Community and regional food planning: Building institutional support in the United States. International Planning Studies, 14, 349-367. https://doi.org/10.1080/13563471003642902

Powell, L. M., Auld, M. C., Chaloupka, F. J., O’Malley, P. M., \& Johnston, L. D. (2007). Associations between access to food stores and adolescent body mass index. American Journal of Preventive Medicine, 33(4), S301-S307. https://doi.org/10.1016/j.amepre.2007.07.007

Ridley, W., \& Devadoss, S. (2020). The effects of COVID-19 on fruit and vegetable production. Applied Economic Perspectives and Policy, 43(1), 329-340. https://doi.org/10.1002/aepp.13107

Smith, D., Miles-Richardson, S., Dill, L., \& Archie-Booker, E. (2013). Interventions to improve access to fresh food in vulnerable communities: A review of the literature. International Journal on Disability and Human Development, 12(4), 409-417. https://doi.org/10.1515/ijdhd-2013-0203

Testa, A. (2019). The association between food deserts and short sleep duration among young adults in the United States: Variation by race and ethnicity. Sleep Health, 5(2), 128-134. https://doi.org/10.1016/j.sleh.2018.11.006

Thilmany, D., Canales, E., Low, S. A., \& Boys, K. (2020). Local food supply chain dynamics and resilience during COVID-19. Applied Economic Perspectives and Policy, 43(1), 86-104. https://doi.org/10.1002/aepp.13121

U.S. Department of Agriculture, Economic Research Service [USDA ERS]. (2017). Independent grocery stores in the changing landscape of the U.S. food retail industry (Economic Research Paper Report No. ERR-240). Retrieved from https://www.ers.usda.gov/publications/pub-details/?pubid=85782

USDA ERS. (2019). The 2018 current Population Survey Food Security Supplement, U.S. Census Bureau. https://www.ers.usda.gov/data-products/chart-gallery/gallery/chart-detail/?chartId=58384

USDA ERS. (2020). Food Access Research Atlas Documentation. Retrieved from https://www.ers.usda.gov/data-products/food-access-research-atlas/documentation/

Vaughan, C. A., Cohen, D. A., Ghosh-Dastidar, M., Hunter, G. P., \& Dubowitz, T. (2017). Where do food desert residents buy most of their junk food? Supermarkets. Public Health Nutrition, 20(14), 2608-2616. https://doi.org/10.1017/S136898001600269X

Walker, R., Keane, C., \& Burke, J. (2010). Disparities and access to healthy food in the United States: A review of food deserts literature, Health \& Place, 16(5), 876-884. https://doi.org/10.1016/i.healthplace.2010.04.013

Widener, M. J., Metcalf, S. S., \& Bar-Yam, Y. (2013). Agent-based modeling of policies to improve urban food access for low-income populations. Applied Geography, 40, 1-10. https://doi.org/10.1016/j.apgeog.2013.01.003

$\mathrm{Xu}, \mathrm{M}$. (2014). A GIS-based pedestrian network model for assessment of spatial accessibility equity and improvement prioritization and its application to the Spokane public transit benefit area. (Doctoral Dissertation). Interdisciplinary Design Institute, Washington State University, Pullman, Washington. Retrieved from http://hdl.handle.net/2376/5170

Yaffe-Bellany, D. \& Corkery, M. (2020, April 11). Dumped milk, smashed eggs, plowed vegetables: Food waste of the pandemic. New York Times. https://www.nytimes.com/2020/04/11/business/coronavirus-destroying-food.html

Zachary, D. A., Palmer, A. M., Beckham, S. W., \& Surkan, P. J. (2013). A framework for understanding grocery purchasing in a low-income urban environment. Qualitative Health Research, 23(5), 665-678.

https://doi.org/10.1177/1049732313479451 
Zenk, S. N., Schulz, A. J., Israel, B. A., James, S. A., Bao, S., \& Wilson, M. L. (2005). Neighborhood racial composition, neighborhood poverty, and the spatial accessibility of supermarkets in metropolitan Detroit. American Journal of Public Health, 95(5), 660-667. https://doi.org/10.2105/AJPH.2004.042150

Ziliak, J. P. (2020). Food hardship during the Covid-19 pandemic and Great Recession. Applied Economic Perspectives and Policy, 43(1), 132-152. https:/ / doi.org/10.1002/aepp.13099 